\title{
COMPARISION OF PHYTOCHEMICALS IN THE FLOWER BUDS, PEDICELS AND LEAVES OF SYZYGIUM AROMATICUM (L.) MERRIL AND PERRY
}

\author{
RAJALEKSHMY V. S. ${ }^{*}$, V. MANIMEKALAI \\ Department of Botany, Sri Parasakthi College for Women, Courtallam. India \\ Email: sehimaravi@gmail.com
}

Received: 16 Oct 2018, Revised and Accepted: 10 Dec 2018

\section{ABSTRACT}

Objective: To analyse and compare the major chemical components in the flower buds, pedicels and leaves of Syzygium aromaticum by GasChromatography Mass spectrometry technique.

Methods: Healthy and mature flower buds, pedicels and leaves were shade dried and pulverized using a mechanical grinder. The powder was successively extracted with ethanol $(40-60 \mathrm{o}$ C). The extracts were concentrated under reduced pressure in a rotary evaporator. The ethanolic extracts of the plant parts such as leaves, pedicels, and buds were used for GC-MS analysis.

Results: The major constituent is eugenol. Pedicels contain 79.75\% eugenol, buds contain $74.12 \%$ eugenol and leaves contain $51.03 \%$ eugenol. In addition to eugenol, other important components are Acetyl eugenol, Caryophyllene, Humulene and Caryophyllene oxide.

Conclusion: Eugenol has a wide range of medicinal properties such as antiseptic, anaesthetic, analgesic anti-inflammatory. Commercially pedicel is not used for eugenol extraction. Present study has revealed that it could be used as a promising one in pharmaceutical industry in addition to flower buds.

Keywords: GC-MS, Clove buds, Pedicel, Eugenol, Caryophyllene.

(C) 2019 The Authors. Published by Innovare Academic Sciences Pvt Ltd. This is an open-access article under the CC BY license (http://creativecommons.org/licenses/by/4.0/) DOI: http://dx.doi.org/10.22159/ijcpr.2019v11i1.31991

\section{INTRODUCTION}

Syzygium aromaticum is a tree of the Family Myrtaceae and its aromatic dried flower buds are of economic importance. They are native to Maluku Islands in Indonesia and are commonly used as a spice. Cloves are commercially harvested in India, Pakistan, Indonesia, Madagascar, Zanzibar, Srilanka, and Tanzania. The term Clove is derived from the French word 'Clou' and the English word 'Clout', both meaning 'nail' from the likeliness of the flower bud of the clove tree to a broad-headed nail. Syzygium aromaticum is an evergreen tree which grows to a height ranging from $8-12 \mathrm{~m}$ having large leaves and sanguine flowers in numerous group of terminal cymose clusters [I]. Flowers are hermaphrodite and self-pollinating. Each peduncle bears 3-4 stalked flowers at the end. The flower buds are at first of a pale colour and gradually become green, after which they develop into a bright red when they are ready for harvest and collection. Cloves are harvested when 1.5-2 cm long consist of a long axis terminating in four spreading sepals and four unopened petals which form a ball at the centre. Then these flower buds of cloves are sundried.

Good quality clove buds contain $15-20 \%$ essential oil. The oil is dominated by eugenol (70-85\%), eugenyl acetate $(15 \%)$ and $\beta$ Caryophyllene.(5-12\%) which together make up 99\% of the oil [2]. Clove is one of the major vegetal sources of phenolic compounds such as hydroxyl benzoic acid, hydroxyl cinnamic acid, and hydroxyl phenylpropenes. Phenolic acids and gallic acids are the main compounds found in higher concentration [3]. Other phenolic compounds are caffeic, ferulic, elagic and salicylic acids. Flavonoids as kaempferol, quercetion are present in lower concentration. Another important compound is $\alpha$ humulene other volatile compounds present in a lower concentration in clove oil are $\beta$ pinene, limonene, farnesol, benzaldehyde and 2-heptanone.

Clove leaves yield 3.0-4.8 \% essential oil. The essential oil content especially eugenol increases during different stages of leaf growth from 38.3 to $95.2 \%$ with maturity while the contents of eugenyl acetate and caryophyllene decrease [2]. Clove bud oil and leaf oil contain various classes of compounds eg: monoterpenes, Sesquiterpenes, aldehydes, and ketones. Clove stem yield $6 \%$ volatile oil which contains $80.2 \%$ eugenol and $6.6 \% \beta$-caryophyllene, besides several minor components. Ripe fruits yields $2 \%$ of oil which comprised 50-55\% eugenol.

Eugenol glucoside gallate, a Chromone C-glucoside, galloyl and hexahydroxy diphenyl esters of 2, 4-6, trihydroxy acetophenone-3gluco pyranoside have been isolated from clove leaves [4]. Further two ellagitanins namely syzygin A and syzygin B have also been isolated from leaves.

Clove is a naturally occurring food flavour and is extensively used in fragrance and flavour formulations for its spicy aroma. Clove oil is found to be more effective against some foodborne pathogens [5]. It is used a food preservative. Saponins are also present in cloves [6]. It is also used in the soap industry.

The most prominent use of clove oil is in dental care. The germicidal properties of the oil make it very effective for relieving dental pain, toothache sore gums and mouth ulcers [7]. Gargles with diluted clove oil help in easing the throat. The characteristic smell of clove oil helps removing bad breath. As a result clove oil is added to numerous dental products and medications including mouthwashes and toothpaste.

\section{MATERIALS AND METHODS}

Healthy and mature flower buds, pedicels and leaves were collected from clove trees in kollam district of Kerala. During the months of November-January, They were shade dried and pulverized using a mechanical grinder. The powder was successively extracted with ethanol $(40-60 \mathrm{o} C)$. The extracts were concentrated under reduced pressure in a rotary evaporator. The ethanolic extracts of the plant parts such as leaves, pedicels, and buds were used for GC-MS analysis.

\section{GC-MS analysis}

GC-Ms analysis was carried out on a GC Clarus 500 Perkin Elmer System and gas chromatograph interfaced to a mass spectrometer instrument employing the following conditions: Column Elite-I fused Silica capillary column $(30 \mathrm{~mm} \times 0.25 \mathrm{mmID} \times 1 \mathcal{M}$ Mdf, Composed of $100 \%$ Dimethyl poly Siloxane) operating in electron impact mode at $70 \mathrm{eV}$; Helium (99.99\%) was used as carrier gas at a constant flow of $1 \mathrm{ml} / \mathrm{min}$ and an injection volume of $2 \mu \mathrm{l}$ was employed (Split ratio 
of 10:1) Injector temperature $250^{\circ} \mathrm{C}$; Ion source temperature 280 ${ }^{\circ} \mathrm{C}$. The oven temperature was programmed from $110^{\circ} \mathrm{C}$ (isothermal for $2 \mathrm{~min}$ ) with an increase of $10{ }^{\circ} \mathrm{C} / \mathrm{min}$, to $200{ }^{\circ} \mathrm{C}$, then 5 ${ }^{\circ} \mathrm{C} /$ minute to $280{ }^{\circ} \mathrm{C}$, ending with a $9 \mathrm{~min}$. isothermal at $280^{\circ} \mathrm{C}$. Mass spectra were taken at $70 \mathrm{eV}$; a scan interval of 0.5 seconds and fragments from 45 to $450 \mathrm{Da}$. Total GC running time was $36 \mathrm{~min}$. Interpretation on mass spectrum GC-MS was conducted using the database of NIST. The spectrum of the unknown component was compared with the spectrum of the known components stored in the NIST library.

\section{RESULTS AND DISCUSSION}

GC-MS analysis was carried out in the powdered clove buds, Pedicels and leaves. The results are given in the table 1 and graphs 1.4

Table 1: Major chemical components of the flower buds, pedicels and leaves of Syzygium aromaticum (L.) merril and perry

\begin{tabular}{llll}
\hline S. No. & Name of the compound & \multicolumn{2}{l}{ Plant parts (Area of \%) } \\
\cline { 3 - 4 } & & Bud & \multicolumn{2}{c}{ Pedicel } \\
\hline 1 & Eugenol & 74.12 & 79.75 \\
2 & Acetyleugenol & 6.69 & 0.051 \\
3 & Caryophyllene & 6.538 & 5.46 \\
4 & Humulene & 0.871 & 0.11 \\
5 & Caryophyllene Oxide & 0.482 & 2.199 \\
\hline
\end{tabular}

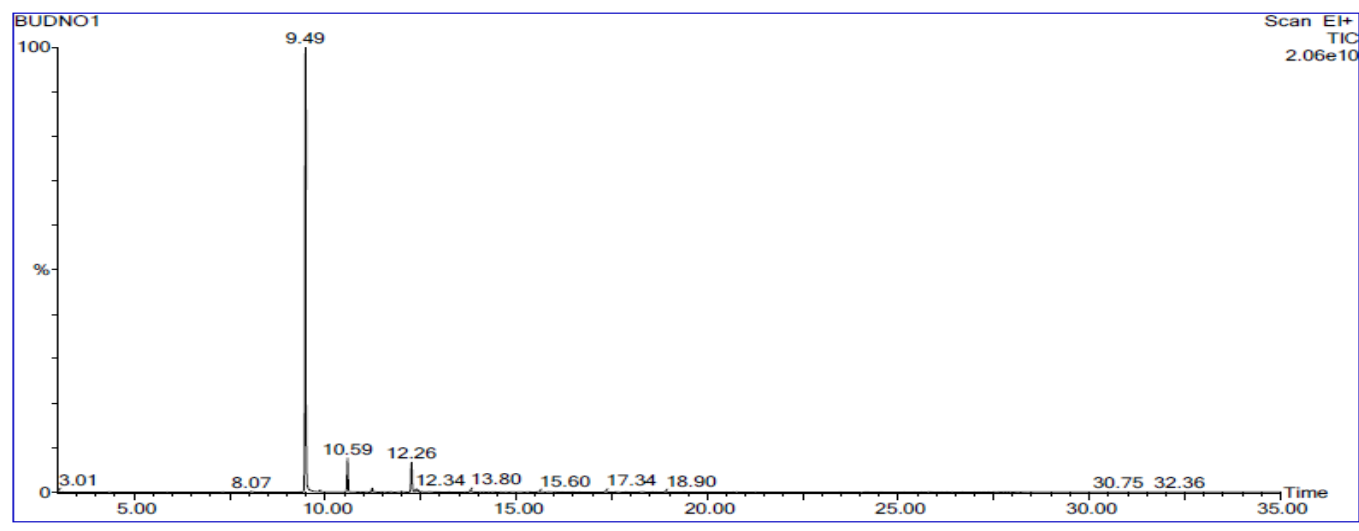

Graph 1: GC-MS chromatogram profile of flower buds of Syzygium aromaticum (L.) Merril and perry

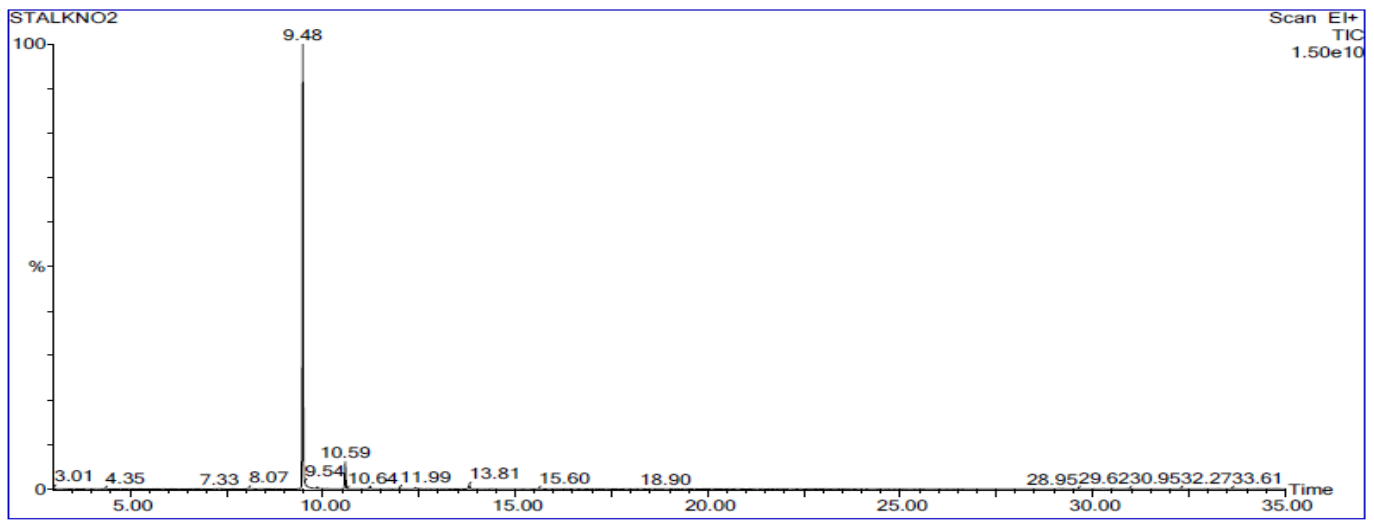

Graph 2: GC-MS chromatogram profile of pedicels of syzygium aromaticum (L.) merril and perry

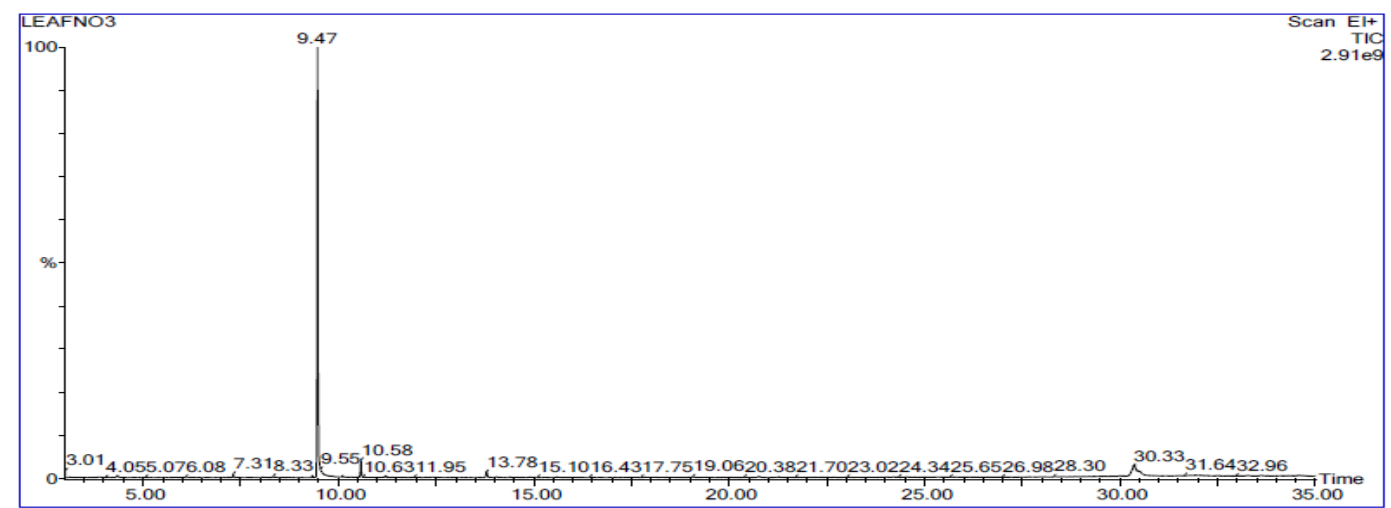

Graph 3: GC-MS chromatogram profile of leaves of syzygium aromaticum (L.) merril and perry 


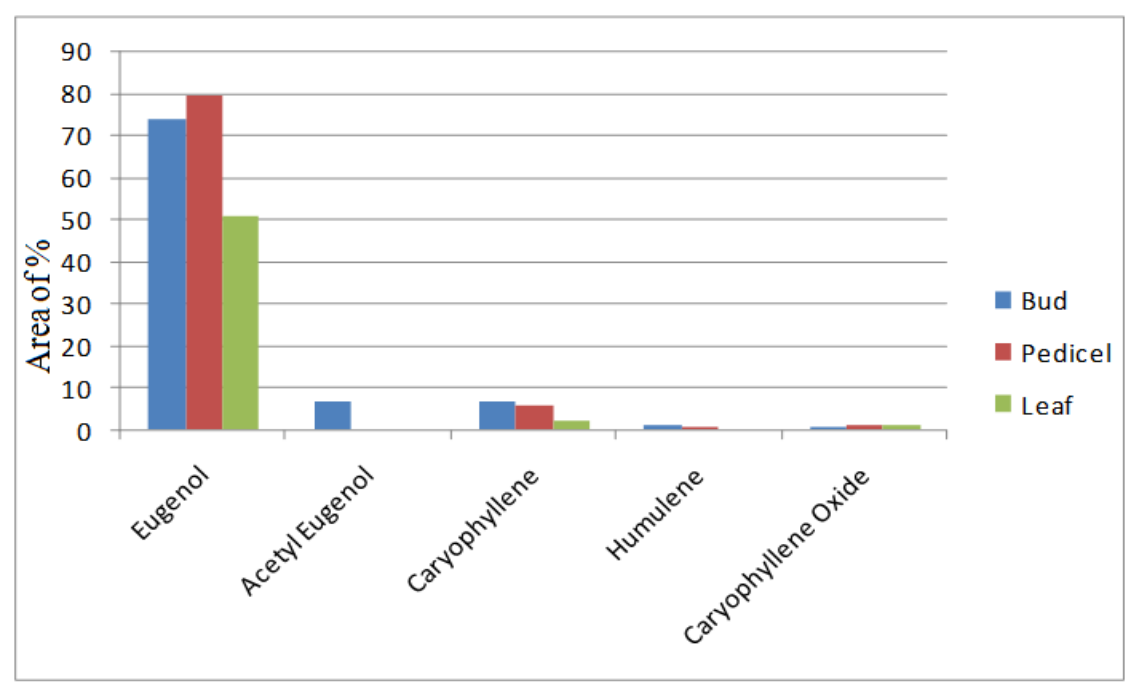

Graph 4: Comparison of major phytochemicals in flower buds, pedicels and leaves of syzygium aromaticum (L.) merril and perry

Eugenol was found to be the main compound present in the buds, pedicels, and leaves. In bud eugenol was $74.12 \%$ in pedicel it was $79.75 \%$ and in leaves, it was $51.03 \%$. In addition to this, Acetyl eugenol, Caryophyllene, Caryophyllene oxide, humulene are also present. Present study shows that the concentration of eugenol is highest in pedicel. Eugenol constitutes a potential antitumor compound against different kinds of Cancer cells depending up on their sensitivity towards it [8]. Eugenin isolated from clove buds show antiviral activity against Herpes Simplex Virus.

In addition to the above-mentioned compounds, certain other compounds are present in lower concentration. Some of them present in bud include Octadecane, alfa-copaene, ulangene, cubenene, isocaryophyllene, Bisa-bolane Naphthalene, Silane, GermacreneD Aromadendrene, $\mathrm{Cis}$ and trans calamenene, doconexent, farnesol, Milbemycin, Rhodopin, Toluene, 2, 6dihydroxy acetophenone, Retinol, Strychane, arachidonic acid, hexa decanoic acid, Lysergic acid, propanoic acid, Tocopherol. Other compounds present in leaf includes 2, 6 dihydroxy acetophenone, Strychane, demecolcine, phentolamine, a-acorneol, hydrocortisone, dodecane, Malonic acid, Memantine, Myristic acid, arachidonic acid, stearic acid, Silane, allo aroma dendrane etc. Other compounds present in pedicel include dodecane, doconexent, farnesene, Memantine, quinolin, carvacrol, alfa copaene, ylangene, allo aroma dendrene, Cis and Tran's calamenene, Stearic acid, Formic acid, 2, 6dihydroxy acetophenone.

Clove is rich in minerals such as Calcium, Iron, Mg, Pottassium, Magnesium Phosphorus, Zinc Copper, Manganese, Selenium, Vitamin $\mathrm{A}, \mathrm{B}_{6}, \mathrm{E}$ and $\mathrm{K}[9]$. One $\mathrm{Kg}$ of dried buds yield approximately $150 \mathrm{ml}$ of eugenol Eugenol cause toxic relatively small quantities as lower $5 \mathrm{ml}$ [10] Clove oil can be extracted from the leaves, Stem, and buds of clove plant. The main chemical component of clove oil are eugenol, eugenol acetate and caryophyllene [11]. Clove oil is a potential source of bioactive compounds against some bacteria in during nosocomial infections in neonate intensive care Units. [12] Clove oil shows potent insecticidal activity [13]. Clove and eugenol possess strong antioxidant activity.

Eugenol has a wide range of medicinal value such as antiseptic anaesthetic analgesic anti-inflammatory and antimicrobial activities [14]. Clove is used as a carminative to increase hydrochloric acid in the stomach and to improve peristalsis. Eugenol is powerful enough for preventing blood clots. Clove enhances memory retention. It is recommended for brain fog, lethargy and depressive state of mind.

\section{CONCLUSION}

The chemical composition of dried clove buds, pedicels and leaves were investigated. Pedicel shows highest concentration of eugenol than buds and leaves. Commercially pedicel is not used for eugenol extraction. But this study has shown that pedicel can also be used as a promising one to the pharmaceutical industry in addition to buds.

\section{AUTHORS CONTRIBUTIONS}

All the author have contributed equally

\section{CONFLICT OF INTERESTS}

Declare none

\section{REFERENCES}

1. Mohammed Ali. Text book of pharmacognosy CBS publishers and distributors. 4596/1 11 DARYA GANJ, NEW DELHI110002; 2009. p. 196-8, 433-5.

2. Parle Milind, Khanna Deepa. Clove: a champion spice. Int J Res Ayurveda Pharm 2011;2:47-54.

3. Khalid Abdual Kreen Mohammed, H Mustaja Abdul Kadhim, Sawsan I Noori. Chemical composition and anti-bacterial effects of clove (Syzygium aromaticum) flowers. Int J Curr Microbiol Appl Sci 2016;5:483-9.

4. Takashi Tanaka, Yuriko Orii, Gen Ichiro Nonaka, Itsuo Nishioka. Tannins and related compounds. CXXIII. chromone, Acetophenone and phenylpropanoid glycosides and their galloyl and/or hexahydroxy diphenoyl esters from the leaves of syzygium aromaticum MERR. et PERRY. Chem Pharm Bull 1993;41:1232-7.

5. Amit Pandey, Parul Singh. Antibacterial activity of syzygium aromatium (Clove) with metal ion effect against foodborne pathogens. Asian J Plant Sci Res 2011;1:69-80.

6. Deepali D Kadam, Pramod C Mane, Ravindra D Chaudhari. Phytochemical screening and pharmacological applications of some selected Indian spices. Int J Sci Res 2015;4:74-6.

7. Deepanjeet Kaur, Kaushal K Chandrual. Syzygium aromaticum L. (Clove): a vital herbal drug used in peridontal disease. Indian J Pharm Biol Res 2017;5:45-51.

8. Vinay Dwivedi, Richa Shrivastava, Shiwket Hussain, Chaiti Ganguly, Mausumi Bharadwaj. Comparative anticancer potential of clove (Syzygium aromaticum)-an Indian spiceagainst cancer cell lines of various anatomical origin. Asian Pacific J Cancer Prevention 2011;2:1989-93.

9. Abdel Moneim E Sulieman, I Man MO EI Boshraand, EI Amin A EI Khaifa. Nutritive value of clove (Syzygium aromaticum) and detection of the antimicrobial effect of its bud oil. Res J Microbiol 2007;2:266-71.

10. Hema R, Kumaravd S, Sivasubramanian C. GEMS study on the potentials of syzygiium aromaticum. Res 2010;2:1-4.

11. Rahimi AA, Ashnagar, Nikoei Hamideh. Isolation and characterization of 4-allyl-2-methoxy phenol(eugenol) from clove buds marketed in tehran city of Iran. Int J Chem Tech Res 2012;4:105-8. 
12. Amal Taroq, Fatima EI Kamari, Bouchra Oumokhtar, Imane Aouam, Yassine EI Atki Badiaa Lyoussi, Abdelfattab Abdellaocei. Phytochemical screening of the essential of syzygium aromatium and antibacterial activity against nocosomial infections in neonatal activity intensive care. Int J Pharm Sci Rev Res 2018;48:58-61.
13. Grace Metome, Euloge S Adjou, Bertin A Gbaguidi, Edwige Dahouenon Ahoussi, Dominique Sohounhloue. Insecticidial and repellent effects of essential oils of Cinnamomum zeylanicum and syzygium aromaticum from benin against the weevil of pigeon pea. J Pharmacogn Phytochem 2017;6:2074-7.

14. Mishra RP, Sharma Kalyani. Antimicrobial activities of syzygium aromaticum L. (Clove). Int Res J Biological Sci 2014;3:22-5. 